\title{
Vertebral artery aneurysms and the risk of cord infarction following spinal artery coverage during flow diversion
}

\author{
Adam A. Dmytriw, MD, MSc, ${ }^{1-3}$ Anish Kapadia, MD, ${ }^{1,2}$ Alejandro Enriquez-Marulanda, MD, ${ }^{3}$ \\ Carmen Parra-Fariñas, MD, ${ }^{1}$ Anna Luisa Kühn, MD, PhD, ${ }^{3}$ Patrick J. Nicholson, MB, ChB, BAO, ${ }^{2}$ \\ Muhammad Waqas, MBBS, ${ }^{5}$ Leonardo Renieri, MD, ${ }^{6}$ Caterina Michelozzi, MD, ${ }^{7}$ \\ Paul M. Foreman, MD, ${ }^{4}$ Kevin Phan, MD, MSc, MPhil, ${ }^{3}$ I-Hsiao Yang, MD, ${ }^{2,8}$ \\ Vincent M. Tutino, PhD, ${ }^{5}$ Christopher S. Ogilvy, MD, Ivan Radovanovic, MD, PhD, ${ }^{2}$ \\ Mark R. Harrigan, MD, ${ }^{7}$ Adnan H. Siddiqui, MD, PhD, ${ }^{5}$ Elad I. Levy, MD, MBA, ${ }^{5}$ \\ Nicola Limbucci, MD, ${ }^{6}$ Christophe Cognard, MD, ${ }^{9}$ Timo Krings, MD, PhD, ${ }^{3}$ \\ Vitor Mendes Pereira, MD, MSc, ${ }^{3}$ Ajith J. Thomas, MD, ${ }^{1}$ Thomas R. Marotta, MD, ${ }^{2}$ and \\ Christoph J. Griessenauer, MD ${ }^{10,11}$
}

\begin{abstract}
1Division of Diagnostic and Therapeutic Neuroradiology, St. Michael's Hospital, Toronto; '2Department of Medical Imaging \& Neurosurgery, Toronto Western Hospital, University Health Network, Toronto, Ontario, Canada; ${ }^{3}$ Neurosurgery \& Neuroradiology Service, Beth Israel Deaconess Medical Center, Harvard Medical School, Boston, Massachusetts; ${ }^{4}$ Orlando Health, Neuroscience and Rehabilitation Institute, Orlando, Florida; ${ }^{2}$ Department of Neurosurgery, State University of New York at Buffalo, New York; ' Department of Interventional Neuroradiology, University of Florence, Italy; ${ }^{7}$ Department of Neurosurgery, University of Alabama at Birmingham, Alabama; ${ }^{8}$ Department of Medical Imaging, Kaohsiung Medical University Hospital, Kaohsiung, Taiwan; ' Department of Diagnostic and Therapeutic Neuroradiology, Toulouse University Hospital, Toulouse, France; ${ }^{10}$ Department of Neurosurgery, Geisinger Health System, Danville, Pennsylvania; and ${ }^{11}$ Research Institute of Neurointervention, Paracelsus Medical University, Salzburg, Austria
\end{abstract}

OBJECTIVE Coverage of the anterior spinal artery (ASA) ostia is a source of considerable consternation regarding flow diversion (FD) in vertebral artery (VA) aneurysms due to cord supply. The authors sought to assess the association between coverage of the ASA, posterior spinal artery (PSA), or lateral spinal artery (LSA) ostia when placing flow diverters in distal VAs and clinical outcomes, with emphasis on cord infarction.

METHODS A multicenter retrospective study of 7 institutions in which VA aneurysms were treated with FD between 2011 and 2019 was performed. The authors evaluated the risk of ASA and PSA/LSA occlusion, associated thromboembolic complication, complications overall, aneurysm occlusion status, and functional outcome.

RESULTS Sixty patients with 63 VA and posterior inferior cerebellar artery aneurysms treated with FD were identified. The median aneurysm diameter was $7 \mathrm{~mm}$ and fusiform type was the commonest morphology (42.9\%). During a procedure, $1(61.7 \%)$ or $2(33.3 \%)$ flow diverters were placed. Complete occlusion was achieved in $71.9 \%$. Symptomatic thromboembolic complications occurred in $7.4 \%$ of cases and intracranial hemorrhage in $10.0 \%$ of cases. The ASA and PSA/LSA were identified in $51(80.9 \%)$ and $35(55.6 \%)$ complications and covered by the flow diverter in $29(56.9 \%)$ and $13(37.1 \%)$ of the procedures, respectively. Patency after flow diverter coverage on last follow-up was $89.2 \%$ for ASA and $100 \%$ for PSA/LSA, not significantly different between covered and noncovered groups $(p=0.5$ and $p>0.99$, respectively). No complications arose from coverage.

CONCLUSIONS FD aneurysm treatment in the posterior circulation with coverage of ASA or PSA/LSA was not associated with higher rates of occlusion of these branches or any instances of cord infarction.

https://thejns.org/doi/abs/10.3171/2020.1.JNS193293

KEYWORDS intracranial aneurysm; stent; embolization; spinal cord; posterior circulation; vascular disorders

ABBREVIATIONS AICA = anterior inferior cerebellar artery; $\mathrm{AP}=$ anteroposterior; $\mathrm{ASA}=$ anterior spinal artery; $\mathrm{DSA}=$ digital subtraction angiography; $\mathrm{FD}=$ flow diversion; FRED = Flow Redirection Endoluminal Device; IPH = intraparenchymal hemorrhage; LSA = lateral spinal artery; $\mathrm{mRS}=$ modified Rankin Scale; $\mathrm{PCA}=$ posterior cerebral artery; PED = Pipeline embolization device; PICA = posterior inferior cerebellar artery; PSA = posterior spinal artery; $\mathrm{SAH}=$ subarachnoid hemorrhage; $\mathrm{SCA}=$ superior cerebellar artery; $\mathrm{SDH}=$ subdural hemorrhage; SVB = Silk Vista Baby; VA = vertebral artery.

SUBMITTED December 6, 2019. ACCEPTED January 8, 2020.

INCLUDE WHEN CITING Published online March 27, 2020; DOI: 10.3171/2020.1.JNS193293. 
$\mathrm{F}$ LOw diversion (FD) has become an important tool in the treatment of intracranial aneurysms and is often used for aneurysms that are difficult to treat with traditional endovascular embolization techniques or microsurgery. ${ }^{1-4}$ The potential for occlusion of flow diverter-covered branches with resulting ischemic complications, however, is concerning. This concern is particularly prevalent in the posterior circulation, which is rich in small perforating vessels and where the use of flow diverters remains off-label. ${ }^{5}$ One previous study has evaluated the risk of ischemic complications resulting from branch coverage and occlusion in the posterior circulation, focusing on the major branches such as the posterior cerebral artery (PCA), superior cerebellar artery (SCA), anterior inferior cerebellar artery (AICA), posterior inferior cerebellar artery (PICA), and the vertebral artery (VA). ${ }^{6}$ However, coverage of the anterior spinal artery (ASA), posterior spinal artery (PSA), and lateral spinal artery (LSA) in this circumstance and its clinical sequelae has not been assessed. We studied the association between ASA and PSA/LSA ostia flow diverter coverage, radiographic outcomes, and clinical outcomes, with emphasis on spinal cord infarction.

\section{Methods \\ Study Design}

A multicenter retrospective cohort of prospectively maintained databases from 7 academic institutions in North America and Europe was analyzed between 2011 and 2019. Inclusion criteria were as follows: consecutive adult patients ( $>18$ years old) with VA including PICA aneurysms, both ruptured and unruptured, treated with FD. Devices included were the Pipeline embolization device (PED; Medtronic, Inc.), Flow Redirection Endoluminal Device (FRED; MicroVention), and the Silk Vista Baby (SVB; Balt Extrusion). The decision on device type was at the discretion of the neurointerventionalist. Institutional review board approval was obtained prior to study initiation at all centers, with routine consent waiver for retrospective analysis.

\section{Procedure Details}

The indication for FD was determined at the discretion of the treating neurointerventionalist at each participating institution on an individual patient basis. Patients undergoing elective procedures received dual-antiplatelet therapy, consisting of clopidogrel $75 \mathrm{mg}$ and aspirin 81 or $325 \mathrm{mg}$ daily, for 14 days prior to the procedure. Platelet function assays were performed at the discretion of the participating institution. Clopidogrel nonresponders were identified by established protocols at individual institutions. If a patient was identified as a clopidogrel nonresponder the dose was adjusted accordingly, and a repeated platelet function test was obtained, or the patient was switched to an alternative agent such as ticagrelor or prasugrel. At the discretion of the interventionist, patients undergoing treatment of ruptured aneurysms received either a loading dose of $600 \mathrm{mg}$ of clopidogrel and $325 \mathrm{mg}$ of aspirin or a loading dose of $180 \mathrm{mg}$ of ticagrelor and $81 \mathrm{mg}$ of aspirin prior to the procedure. Intravenous heparin was administered during the procedure to target an activated clotting time of 250-300 seconds. The placement and apposition of the flow diverter to the VA wall was documented by digital subtraction angiography (DSA). Heparin was discontinued after the procedure. Dual-antiplatelet therapy was continued for at least 3 months following flow diverter placement and aspirin $325 \mathrm{mg}$ was continued indefinitely thereafter. All flow diverters were placed in the VA without extension to the vertebrobasilar junction or basilar trunk.

\section{Data Collection}

Patient demographics, aneurysm characteristics, procedural details, and radiographic and clinical outcome variables were collected. Based on the available neurovascular imaging modality, aneurysms were classified as completely occluded (100\%), nearly completely occluded (90\%-100\%), or incompletely occluded $(<90 \%)$ at each radiographic follow-up. Clinical outcome was recorded using the modified Rankin Scale (mRS) score at last follow-up. Complications related to coverage of ASA or PSA/LSA ostia after placement of the flow diverter were defined as new focal neurological deficit attributable to a spinal cord infarction. LSA and PSA were grouped together because DSA does not always permit distinction between these. A permanent complication was defined as one that generated a change in mRS score and was evident on last follow-up.

\section{Statistical Analysis}

Categorical variables were reported as proportions. Continuous variables were reported as mean \pm SD or median (interquartile range [IQR]) as appropriate according to normality. When performing comparisons between groups, categorical variables were compared using the chi-square test. When comparing paired preoperative and postoperative categorical variables the McNemar's test was performed. Statistical significance was set to a $p$ value of less than 0.05. All statistical analyses were performed using the STATA version 14.0 software (StataCorp).

\section{Results}

\section{Patient Characteristics}

Sixty patients with 63 VA and PICA aneurysms treated in 60 procedures with FD were identified. Three patients had 2 VA aneurysms (1 on each VA) that were treated in the same procedure. Thirty-nine $(65.0 \%)$ patients were female with a median age of 57.7 years (Table 1). A total of $13(21.7 \%)$ were smokers, and $14(23.3 \%)$ had multiple intracranial aneurysms. Thirty-nine patients had unruptured aneurysms $(65.0 \%)$, and $10(16.7 \%)$ were acutely ruptured when the flow diverter was placed. VA codominance was the most common anatomical presentation in $28(46.7 \%)$ patients. Clinically, $42(70.0 \%)$ patients had a pretreatment $\mathrm{mRS}$ score of $\leq 2$.

\section{Aneurysm Characteristics}

The median maximal aneurysm diameter was $7 \mathrm{~mm}$, with aneurysms $<7 \mathrm{~mm}$ in size representing $47.5 \%$ of the posterior circulation aneurysms in this sample (Table 1). Fusiform type was the most common morphology in 
TABLE 1. Baseline characteristics in 60 patients with 63 aneurysms

\begin{tabular}{|c|c|}
\hline Variable & Value \\
\hline \multicolumn{2}{|l|}{ Baseline characteristics of patients } \\
\hline No. of patients & $n=60$ \\
\hline \multicolumn{2}{|l|}{ Sex } \\
\hline Female & $39(65.0 \%)$ \\
\hline Male & $21(35.0 \%)$ \\
\hline Median age in yrs (IQR) & $57.7(48.5-65.5)$ \\
\hline Smoking history & $13(21.7 \%)$ \\
\hline Multiple intracranial aneurysms & $14(23.3 \%)$ \\
\hline \multicolumn{2}{|l|}{ Previous SAH } \\
\hline No & $39(65.0 \%)$ \\
\hline$\leq 2$ wks & $5(8.3 \%)$ \\
\hline$>2$ wks & $6(10.0 \%)$ \\
\hline Acutely ruptured & $10(16.7 \%)$ \\
\hline \multicolumn{2}{|l|}{ VA dominance } \\
\hline Lt & $14(23.3 \%)$ \\
\hline Rt & $18(30.0 \%)$ \\
\hline Codominance & $28(46.7 \%)$ \\
\hline \multicolumn{2}{|l|}{ Pretreatment mRS score } \\
\hline 0 & $24(40.0 \%)$ \\
\hline 1 & $11(18.3 \%)$ \\
\hline 2 & $7(11.7 \%)$ \\
\hline 3 & $7(11.7 \%)$ \\
\hline 4 & $4(6.7 \%)$ \\
\hline 5 & $7(11.7 \%)$ \\
\hline Treated aneurysms, baseline characteristics & $n=63$ \\
\hline Median maximal diam in $\mathrm{mm}(\mathrm{IQR})^{\star}$ & $7(3-14)$ \\
\hline$<7$ & $29(47.5 \%)$ \\
\hline $7-9.9$ & $10(16.4 \%)$ \\
\hline $10-19.9$ & $22(36.1 \%)$ \\
\hline$\geq 20$ & $0(0.0 \%)$ \\
\hline \multicolumn{2}{|l|}{ Aneurysm morphology } \\
\hline Saccular & $14(22.2 \%)$ \\
\hline Fusiform & $27(42.9 \%)$ \\
\hline Dissecting/blister & $22(34.9 \%)$ \\
\hline \multicolumn{2}{|l|}{ Aneurysm location } \\
\hline VA & $57(90.5 \%)$ \\
\hline PICA & $6(9.5 \%)$ \\
\hline Intra-aneurysmal thrombus & $16(25.4 \%)$ \\
\hline \multicolumn{2}{|l|}{ Aneurysm type $\dagger$} \\
\hline Sidewall & $58(93.6 \%)$ \\
\hline Bifurcation & $4(6.5 \%)$ \\
\hline Daughter sac & $8(12.7 \%)$ \\
\hline Median parent vessel diam in mm (IQR) & $3.2(1.9-4)$ \\
\hline Major branch covered w/ PED & $50(79.4 \%)$ \\
\hline $\begin{array}{l}\text { Previous treatment of this aneurysm w/ } \\
\text { endovascular coiling }\end{array}$ & $6(9.5 \%)$ \\
\hline
\end{tabular}

Diam = diameter; $I Q R=$ interquartile range.

${ }^{*}$ Missing data in 2 cases.

† Missing data in 1 case.
$42.9 \%$, followed by dissecting/blister type in $34.9 \%$, and by saccular morphology in $22.2 \%$. Six (9.5\%) aneurysms had undergone a previous treatment, which in all cases represented a previous endovascular coiling procedure.

\section{FD Procedure Details}

There were 60 procedures performed (Table 2); most aneurysms were treated with FD alone (83.3\%). In terms of the type of flow diverter used the most frequent one was the PED (96.6\%), followed by FRED and SVB, which together represented only $3.4 \%$ of this series. In most of the cases, $1(61.7 \%)$ or $2(33.3 \%)$ flow diverters were placed in the parent vessel. Platelet function assay test was performed in $35(58.3 \%)$ procedures, of which 8 (22.9\%) cases were classified as clopidogrel nonresponders. The most common antiplatelet regimen postprocedure was aspirin and clopidogrel (88.4\% of cases).

\section{Complications per Procedure}

Nine (15.0\%) patients developed cerebral thromboembolic complications and 4 of them (7.4\%) were symptomatic (Table 2). From the overall sample of patients, cerebellar infarcts occurred in 6 cases (10.0\%), PCA territory infarct in 3 cases $(5.0 \%)$, and brainstem infarct in 2 cases (3.3\%). From the 9 patients who had thromboembolic complications, 2 had infarcts in two or more territories (one patient had brainstem, cerebellum, and PCA infarctions, and the other patient had brainstem and cerebellum infarctions). Symptomatic thromboembolic complications occurred in 2 (22.2\%) of 9 cases with acutely ruptured aneurysms versus $2(4.0 \%)$ of 50 nonacutely ruptured cases $(\mathrm{p}=0.06)$. On the other hand, $6(10.0 \%)$ patients developed hemorrhagic complications, all of which were symptomatic. From the overall sample of patients, the types of hemorrhagic complications were subarachnoid hemorrhage (SAH) in $3(5.0 \%)$ cases, intraparenchymal hemorrhage (IPH) in 2 (3.3\%) cases, and IPH and subdural hemorrhage (SDH) in $1(1.7 \%)$ case. Symptomatic hemorrhagic complications occurred in $3(30.0 \%)$ cases with acutely ruptured aneurysms versus $3(6.0 \%)$ nonacutely ruptured cases $(p=0.02)$.

\section{Follow-Up}

From the total 60 patients with aneurysms treated, clinical follow-up was available in all of them and imaging follow-up for the aneurysms was available in 57 cases (Table 3). Complete occlusion was achieved in $71.9 \%$ of the aneurysms at a median of 12.7 months postprocedure. Good neurological outcome ( $\mathrm{mRS} \leq 2)$ was achieved in 47 $(81.0 \%)$ cases. Only 2 cases $(3.5 \%)$ were re-treated. Death occurred in 5 cases $(8.6 \%)$, due either to initial SAH or to intracranial hemorrhagic complication after the flow diverter placement. Of these, 3 deaths $(5.0 \%)$ were a direct consequence of the device placement.

\section{Coverage of ASA and Related Outcomes}

Information regarding coverage of the ipsilateral ASA by the flow diverter was available in 51 (80.9\%) aneurysms (Table 4). A total of 29 (56.9\%) cases had coverage of the ASA origin. From the cases in which coverage was 
TABLE 2. Treatment details in 60 patients with 63 aneurysms

\begin{tabular}{|c|c|}
\hline Variable & Value \\
\hline Procedure & $n=60$ \\
\hline FD alone & $50(83.3 \%)$ \\
\hline FD + coils & $10(16.7 \%)$ \\
\hline \multicolumn{2}{|l|}{ Device type } \\
\hline PED & $58(96.7 \%)$ \\
\hline Other (FRED, SVB) & $2(3.3 \%)$ \\
\hline \multicolumn{2}{|l|}{ No. of flow diverters } \\
\hline 1 & $37(61.7 \%)$ \\
\hline 2 & $20(33.3 \%)$ \\
\hline 3 & $2(3.3 \%)$ \\
\hline 5 & $1(1.7 \%)$ \\
\hline Median length of procedure time in mins $(I Q R)^{*}$ & $90(65-139)$ \\
\hline Median length of fluoroscopy time in mins $(I Q R) \dagger$ & $31.3(21.5-38)$ \\
\hline \multicolumn{2}{|l|}{ Preprocedure antiplatelet drug } \\
\hline Aspirin $81-325 \mathrm{mg}+$ clopidogrel $75 \mathrm{mg}$ & $53(88.3 \%)$ \\
\hline Aspirin $325 \mathrm{mg}+$ prasugrel $10 \mathrm{mg}$ & $3(5.0 \%)$ \\
\hline Aspirin $81 \mathrm{mg}+$ ticagrelor $180 \mathrm{mg}$ & $3(5.0 \%)$ \\
\hline Other & $1(1.7 \%)$ \\
\hline Platelet function assay performed & $35(58.3 \%)$ \\
\hline Light transmission aggregometry & $23(65.7 \%)$ \\
\hline VerifyNow & $12(34.3 \%)$ \\
\hline Clopidogrel nonresponders & $8(22.9 \%)$ \\
\hline \multicolumn{2}{|l|}{ Postprocedure antiplatelet drug } \\
\hline Aspirin 81-325 mg + clopidogrel 75 mg & $53(88.3 \%)$ \\
\hline Aspirin $325 \mathrm{mg}+$ prasugrel $10 \mathrm{mg}$ & $4(6.7 \%)$ \\
\hline Aspirin 81 mg + ticagrelor 180 mg & $3(5.0 \%)$ \\
\hline Thromboembolic complications & $9(15.0 \%)$ \\
\hline Symptomatic thromboembolic complications & $4(44.4 \%)$ \\
\hline \multicolumn{2}{|l|}{ Timing of thromboembolic complication } \\
\hline Intraop & $1(11.1 \%)$ \\
\hline Postop & $7(77.8 \%)$ \\
\hline Both intra- \& postop & $1(11.1 \%)$ \\
\hline Brainstem infarct & $2(3.3 \%)$ \\
\hline Cerebellar infarct & $6(10.0 \%)$ \\
\hline PCA territory infarct & $3(5.0 \%)$ \\
\hline $\begin{array}{l}\text { Intracranial hemorrhagic complication, all } \\
\text { symptomatic }\end{array}$ & $6(10.0 \%)$ \\
\hline \multicolumn{2}{|l|}{ Type of hemorrhagic complication } \\
\hline SAH & $3(5.0 \%)$ \\
\hline IPH & $2(3.3 \%)$ \\
\hline IPH \& SDH & $1(1.7 \%)$ \\
\hline Other procedure-related complications & $7(11.7 \%)$ \\
\hline All transient complications & $4(6.7 \%)$ \\
\hline All permanent complications & $3(5.0 \%)$ \\
\hline
\end{tabular}

${ }^{*}$ Missing data in 1 case.

† Missing data in 32 cases.

documented, preoperative filling of ipsilateral ASA was evident in $29(100 \%)$ cases and immediate postoperative filling in $26(92.9 \%, p=0.68)$. In terms of ASA patency
TABLE 3. Outcome of flow diverter placement in 60 patients

\begin{tabular}{|c|c|}
\hline Outcome & Value \\
\hline Aneurysm imaging follow-up & $\mathrm{n}=57$ \\
\hline \multicolumn{2}{|l|}{ Last imaging follow-up } \\
\hline Median elapsed time in mos (IQR) & $12.7(6-26)$ \\
\hline \multicolumn{2}{|l|}{ Occlusion status } \\
\hline Occluded, $100 \%$ & $41(71.9 \%)$ \\
\hline Nearly completely occluded, $90-100 \%$ & $5(8.8 \%)$ \\
\hline Incompletely occluded, $<90 \%$ & $11(19.3 \%)$ \\
\hline \multicolumn{2}{|l|}{ Imaging modality used } \\
\hline DSA & $30(52.6 \%)$ \\
\hline CTA & $9(15.8 \%)$ \\
\hline MRA & $18(31.6 \%)$ \\
\hline Flow diverter in-stent stenosis on follow-up & $12(21.1 \%)$ \\
\hline Clinical follow-up & $n=60$ \\
\hline $\begin{array}{l}\text { Last clinical follow-up, median elapsed time in } \\
\text { mos }(I Q R)^{*}\end{array}$ & $12(6-26.7)$ \\
\hline Re-treatment $†$ & $2(3.5 \%)$ \\
\hline \multicolumn{2}{|l|}{ mRS score at last follow-up† } \\
\hline 0 & $33(56.9 \%)$ \\
\hline $1-2$ & $14(24.1 \%)$ \\
\hline $3-5$ & $6(10.4 \%)$ \\
\hline 6; all-cause mortality & $5(8.6 \%)$ \\
\hline
\end{tabular}

* Missing data in 3 cases.

$\dagger$ Missing data in 2 cases.

on the last follow-up (Fig. 1), there were no significant differences between those covered with the flow diverter and those that were not (19 [86.4\%] vs 14 [93.3\%], $\mathrm{p}=0.5$, respectively). There were no complications related to ASA coverage (Figs. 2 and 3 ).

\section{Coverage of LSA/PSA and Related Outcomes}

Information on coverage status of ipsilateral LSA by the flow diverter was available in $35(55.5 \%)$ procedures (Table 4). A total of 13 (37.1\%) cases had coverage of the LSA origin. The ipsilateral LSA origin was either from the VA in $54.6 \%$ or from the PICA in $45.4 \%$ of procedures. From the cases in which coverage was documented, preoperative filling of ipsilateral LSA was evident in 13 $(100 \%)$ cases and immediate postoperative filling in 10 $(90.9 \%, p=0.78)$. In terms of LSA patency on the last follow-up, there were no significant differences between those covered with the flow diverter and those that were not (5 [100\%] vs 17 [100\%], p > 0.99, respectively). There were no complications related to LSA coverage.

\section{Discussion}

This multicenter study evaluated the association of ASA and PSA/LSA ostia coverage after FD with the risk for spinal infarction to assess whether this was relevant to flow diverter placement in the intracranial VA. The study showed no significant change in ASA or PSA/LSA patency after coverage with an FD stent. Reported patency after flow diverter coverage on last follow-up was $89.2 \%$ for 
TABLE 4. Outcomes for FD in ASA and LSA/PSA in 60 patients with 63 aneurysms

\begin{tabular}{|c|c|c|c|c|}
\hline Outcome & $\begin{array}{c}\text { All } \\
\text { Procedures } \\
\end{array}$ & $\begin{array}{c}\text { Artery } \\
\text { Covered }\end{array}$ & $\begin{array}{c}\text { Artery Not } \\
\text { Covered }\end{array}$ & $\mathrm{p}$ Value \\
\hline \multicolumn{5}{|l|}{ ASA } \\
\hline Ipsilat vessel covered by PED* & $n=51$ & $29(56.9 \%)$ & $22(43.1 \%)$ & \\
\hline Ipsilat vessel preop origin filling† & $n=48$ & $n=29$ & $n=19$ & \\
\hline Yes & $48(100.0 \%)$ & $29(100.0 \%)$ & $19(100.0 \%)$ & \multirow[t]{2}{*}{$>0.99$} \\
\hline No & $0(0.0 \%)$ & $0(0.0 \%)$ & $0(0.0 \%)$ & \\
\hline Immediate post-FD filling of vessel $\ddagger$ & $n=47$ & $n=28$ & $\mathrm{n}=19$ & \\
\hline Yes & $43(91.5 \%)$ & $26(92.9 \%)$ & $17(89.5 \%)$ & \multirow[t]{2}{*}{0.68} \\
\hline No & $4(8.5 \%)$ & $2(7.1 \%)$ & $2(10.5 \%)$ & \\
\hline Last follow-up patency of ipsilat vessel§ & $\mathrm{n}=37$ & $n=22$ & $n=15$ & \\
\hline Yes & $33(89.2 \%)$ & $19(86.4 \%)$ & $14(93.3 \%)$ & \multirow[t]{2}{*}{0.5} \\
\hline No & $4(10.8 \%)$ & $3(13.6 \%)$ & $1(6.7 \%)$ & \\
\hline Complications related to ischemia/infarct & $n=51$ & $n=29$ & $n=22$ & \\
\hline Yes & $0(0.0 \%)$ & $0(0.0 \%)$ & $0(0.0 \%)$ & \multirow[t]{2}{*}{$>0.99$} \\
\hline No & $51(100.0 \%)$ & $29(100.0 \%)$ & $22(100.0 \%)$ & \\
\hline \multicolumn{5}{|l|}{ LSA/PSA } \\
\hline Ipsilat vessel covered by flow diverter $\Upsilon$ & $n=35$ & $13(37.1 \%)$ & $22(62.9 \%)$ & \\
\hline LSA/PSA origin ipsilat** & $n=33$ & $n=13$ & $n=20$ & \\
\hline VA & $18(54.6 \%)$ & $9(69.2 \%)$ & $9(45.0 \%)$ & \multirow[t]{2}{*}{0.17} \\
\hline PICA & $15(45.4 \%)$ & $4(30.8 \%)$ & $11(55.0 \%)$ & \\
\hline Preop origin filling of vessels†† & $n=34$ & $n=13$ & $n=21$ & \\
\hline Yes & $33(97.1 \%)$ & $13(100.0 \%)$ & $20(95.2 \%)$ & \multirow[t]{2}{*}{0.42} \\
\hline No & $1(2.9 \%)$ & $0(0.0 \%)$ & $1(4.8 \%)$ & \\
\hline Immediate post-FD filling of vesselsł‡ & $n=27$ & $n=11$ & $n=16$ & \\
\hline Yes & $24(88.9 \%)$ & $10(90.9 \%)$ & $14(87.5 \%)$ & \multirow[t]{2}{*}{0.78} \\
\hline No & $3(11.1 \%)$ & $1(9.1 \%)$ & $2(12.5 \%)$ & \\
\hline Last follow-up patency of vessels§§ & $n=22$ & $n=5$ & $\mathrm{n}=17$ & \\
\hline Yes & $22(100.0 \%)$ & $5(100.0 \%)$ & $17(100.0 \%)$ & \multirow[t]{2}{*}{$>0.99$} \\
\hline No & $0(0.0 \%)$ & $0(0.0 \%)$ & $0(0.0 \%)$ & \\
\hline Complications related to ischemia/infarct & $\mathrm{n}=35$ & $n=13$ & $n=22$ & \\
\hline Yes & $0(0.0 \%)$ & $0(0.0 \%)$ & $0(0.0 \%)$ & \multirow[t]{2}{*}{$>0.99$} \\
\hline No & $35(100.0 \%)$ & $13(100.0 \%)$ & $22(100.0 \%)$ & \\
\hline $\begin{array}{l}\text { * Missing data in } 12 . \\
\dagger \text { Missing data in } 3 . \\
\ddagger \text { Missing data in } 4 . \\
\S \text { Missing data in } 14 . \\
\text { † Missing data in } 28 . \\
{ }^{* *} \text { Missing data in } 2 . \\
\text { †† Missing data in } 1 . \\
\text { † Missing data in } 8 . \\
\S \S \text { Missing data in } 13 .\end{array}$ & & & & \\
\hline
\end{tabular}

ASA and $100 \%$ for LSA, which was not significantly different compared to procedures in which the ASA or PSA/ LSA were not covered ( $p=5$ and $p>0.99$, respectively). No cases of spinal cord infarction due to branch coverage were identified on follow-up.

\section{FD for Complex Posterior Circulation Aneurysms}

Aneurysms of the posterior circulation have a worse natural history and are more difficult to treat than those in the anterior circulation. ${ }^{7-11}$ For a number of those aneurysms, treatment options are limited. FD has increasingly become more attractive even though the initial experience with FD treatment of complex aneurysms in the posterior circulation was not nearly as promising as in the anterior circulation. ${ }^{7,10,12-14}$ A meta-analysis performed by Brinjikji et al. in 2013 found that aneurysms treated with FD in posterior circulation aneurysms were at increased risk of ischemic stroke, particularly perforator infarction, com- 
Dmytriw et al.

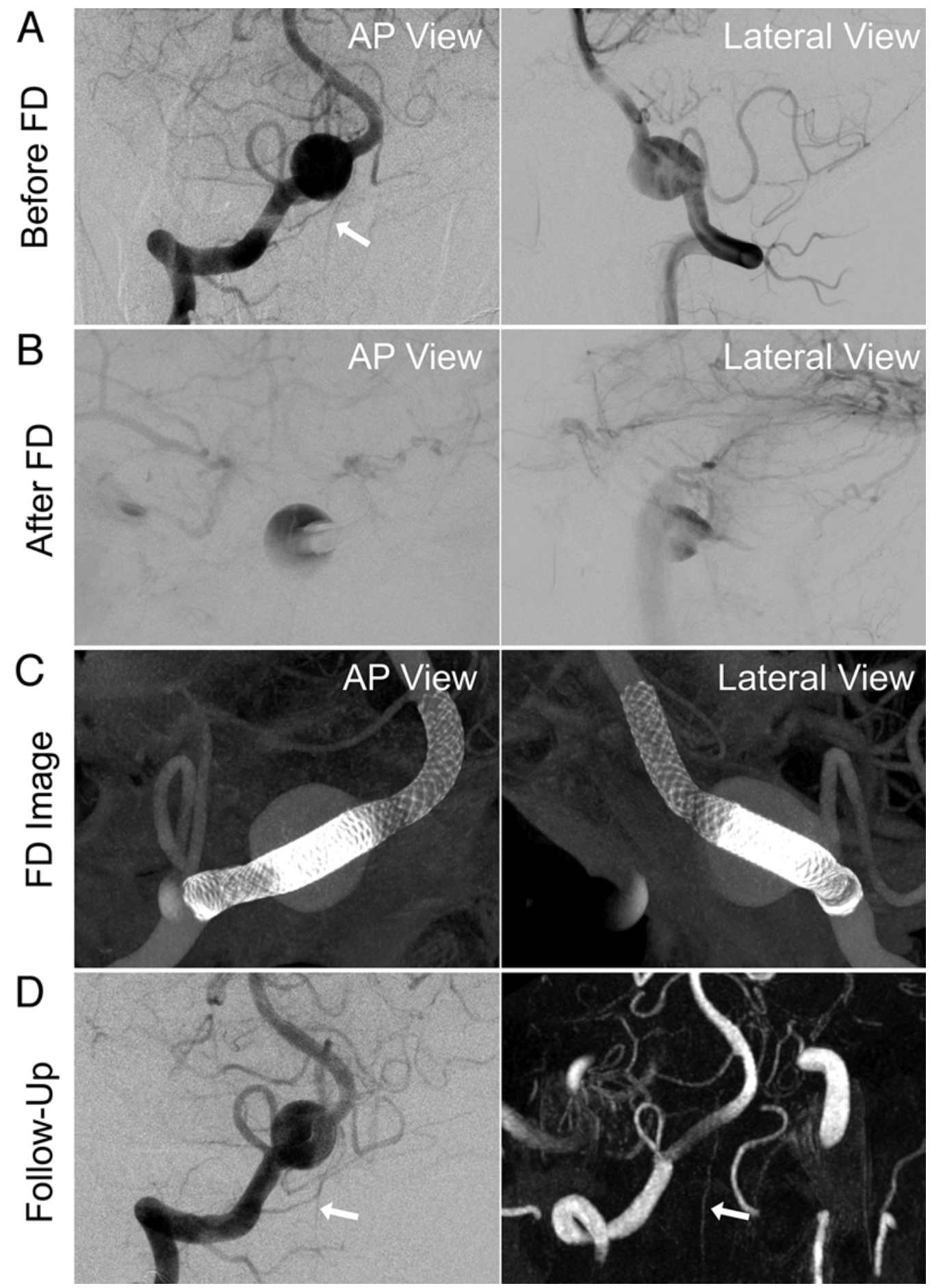

FIG. 1. A 14-mm fusiform-saccular right VA aneurysm treated by FD. A: Anteroposterior (AP) and lateral views of the aneurysm showing the ASA (arrow) in the AP view. B: The aneurysm was treated by 2 telescoping PEDs, which caused moderate stasis after placement. C: 3D DSA and cone-beam CTA demonstrated good apposition of the 2 overlapping PED constructs to the parent vessel with some expected continued filling of the aneurysmal lumen. D: An angiogram (left panel) obtained after treatment demonstrated wide patency of the ASA (arrow), which was covered by the stent. Furthermore, 1-month follow-up MRI (right panel) showed no residual contrast filling in the aneurysm lumen and adequate patency of the ASA (arrow).

pared to those treated in the anterior circulation. ${ }^{15}$ Symptomatic large or giant fusiform vertebrobasilar aneurysms fared particularly poorly with FD. ${ }^{16}$ A more recent meta- analysis of nonsaccular posterior circulation aneurysms performed by Kiyofuji et al. in 2018 reported a periprocedural stroke rate of $23 \%$ and mortality of $21 \%$, underlining 
Dmytriw et al.

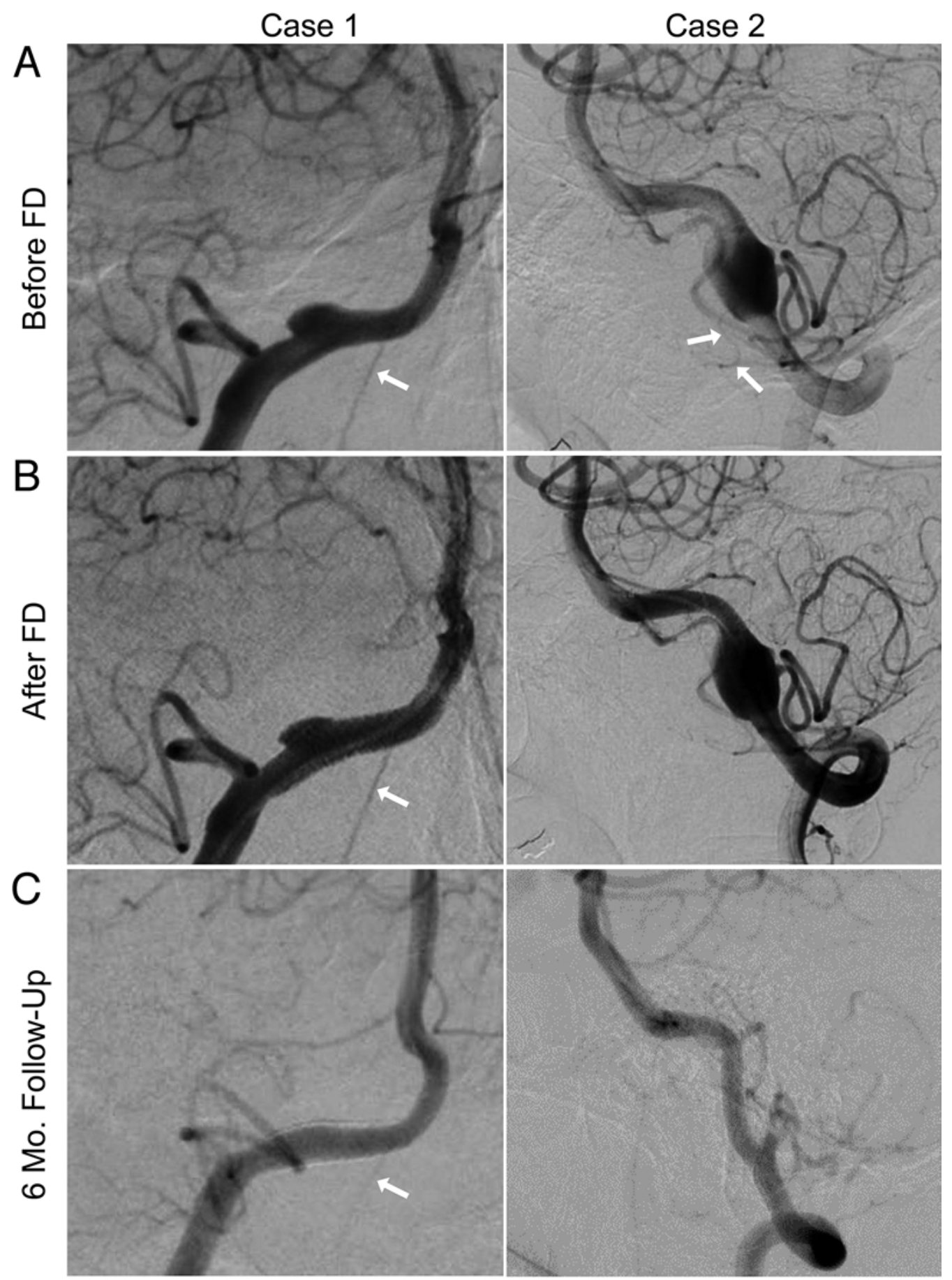

FIG. 2. Two VA aneurysms treated by FD. A: AP view of a right VA injection shows a saccular sidewall right VA aneurysm (case 1) and a fusiform VA aneurysm (case 2). Both angiograms also show the ASA (arrows). B: View after flow diverter stent placement over both aneurysms, including over the opening of the ASA. The ASA in case 1 remains patent (arrow), whereas the ASA in case 2 cannot be seen. C: The 6-month follow-up angiograms show complete occlusion of the aneurysms. There remains persistent filling of the ASA (arrow) in case 1, but in case 2 the ASA was not patent. There were no complications related to ASA coverage in either case.

the potential risk associated with using those devices in the posterior circulation. ${ }^{13}$

Posterior circulation aneurysms most suitable for FD may be those involving the VA proximal to the vertebro- basilar junction of fusiform, dissecting, or blister morphology. The VA has fewer critical perforators than the basilar trunk and there are few alternative endovascular or open surgical treatment options for those aneurysm types. The 


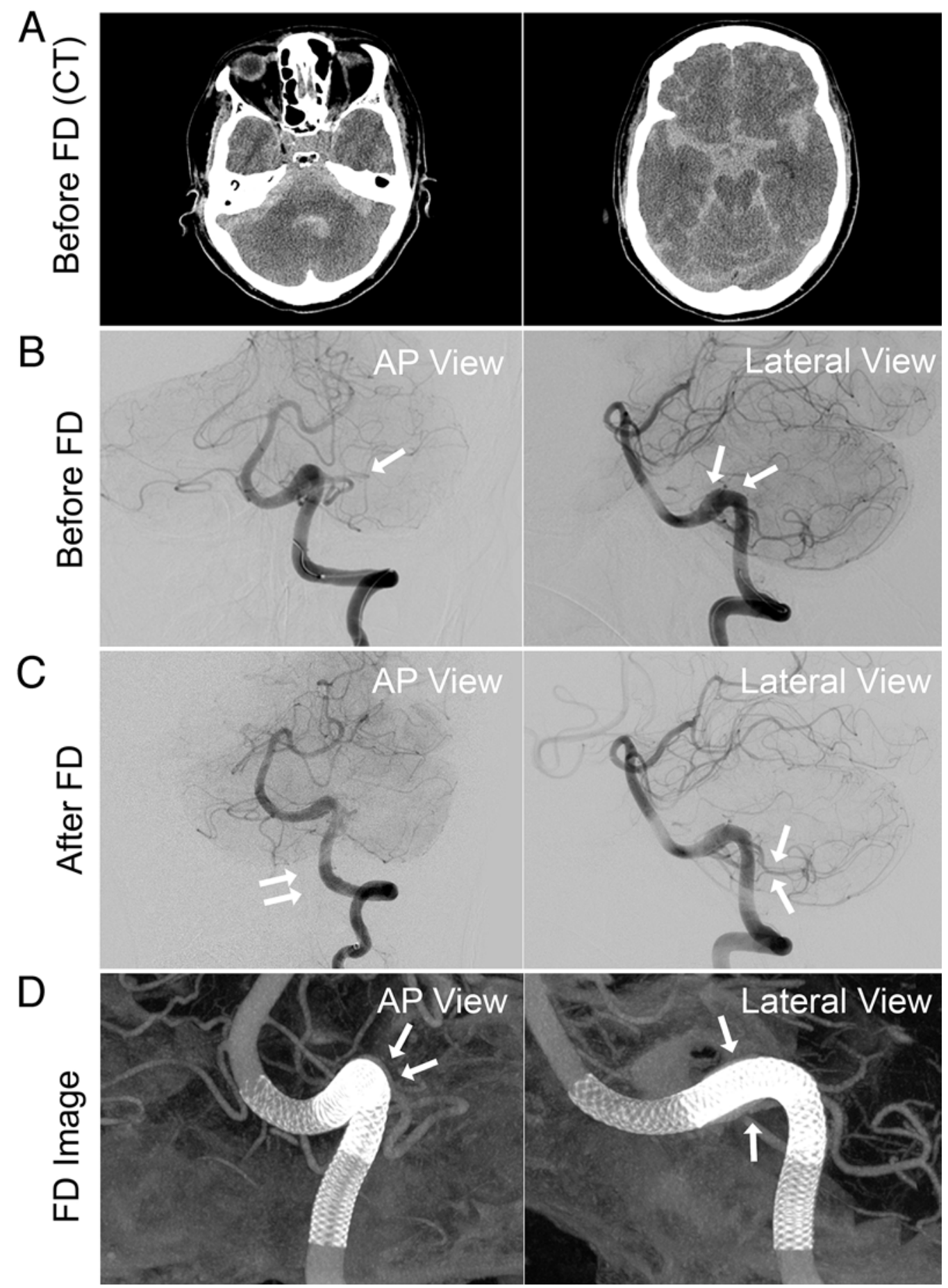

FIG. 3. A dissecting aneurysm on the left VA treated by FD. A: Axial CT head scans demonstrated large-volume SAH throughout the basal cisterns, sylvian fissures, and sulci on the surface of both cerebral hemispheres. B: Cerebral angiography demonstrated a dissecting aneurysm of the post-PICA segment of the left intradural VA along its horizontal course (arrows). C: A cerebral angiogram obtained after endovascular treatment of the left VA dissecting aneurysm was performed using 2 overlapping PEDs (4.25 $\times$ $35 \mathrm{~mm}$ and $4.25 \times 30 \mathrm{~mm}$ ) that were successfully placed across the aneurysmal segment. The ASA (arrows in AP view) and the ipsilateral PICA (arrows in lateral view) remain widely patent. D: 3D rotational angiography and cone-beam CTA demonstrated good apposition of the 2 overlapping PED constructs to the parent vessel with some expected continued filling of the pseudoaneurysmal lumen (arrows). 
largest series to date of 131 posterior circulation aneurysms treated with FD included $55(42 \%)$ aneurysms of the VA or PICA.${ }^{17}$ Of those, $38(69.1 \%)$ were of either dissecting/ blister or fusiform morphology. Overall complication rates among dissecting and fusiform aneurysms of the VA were indeed considerably lower at $16.7 \%$ and $15.8 \%$, respective$1 y$, than for fusiform vertebrobasilar or basilar aneurysms at $35.7 \%$. In our study, we report symptomatic thromboembolic complications in $7.4 \%$ of cases and intracranial hemorrhage in $10 \%$. In the largest series of posterior circulation FD to date, Griessenauer et al. reported symptomatic thromboembolic complications in $17.2 \%-25 \%$ of cases, depending on aneurysm morphology. ${ }^{17}$ Intracranial hemorrhage rates ranged from $3.4 \%$ to $10.4 \%$. We surmise that the reason we have a lower-range thromboembolic rate and a higher-range hemorrhagic rate is that our study comprised a large number of fusiform and blister/dissecting aneurysms. The latter have a higher risk for hemorrhagic complications. Given the fact that a significant number of those dissecting aneurysms were treated in the setting of rupture, we endeavored to segregate these results, showing that hemorrhagic complication was significantly greater in the setting of rupture. This observation raises the question of whether there are potential pitfalls with FD of VA aneurysms, such as complications arising from coverage of the ASA or PSA/LSA, and if coverage of those branches is associated with yet unrecognized consequences.

\section{Aspects of Flow Diverter Branch Coverage in the Posterior Circulation}

There is only one study that has specifically addressed branch coverage with the flow diverter in the posterior circulation. In this multicenter study by Adeeb et al., the vessels assessed were the PCA, SCA, AICA, PICA, and VA. ${ }^{6}$ The rate of branch occlusion overall was $11 \%$ among 228 covered branches. The vessel to most commonly occlude was the VA (34.8\%), followed by the PCA (23.5\%), PICA $(8.2 \%)$, AICA (7.7\%), and SCA (4.9\%). Interestingly, there was no association of complications with covered and noncovered as well as occluded and nonoccluded branches, mirroring reports in the anterior circulation demonstrating that branch occlusion after FD is frequently asymptomatic. There is an increased propensity for covered branch vessels to occlude when they are rich in collateral supply, and thus occlusion often correlates directly with size. ${ }^{6,18-21} \mathrm{On}$ the other hand, covered terminal branches are likely to remain patent due to hemodynamic flow demand. ${ }^{6,22,23}$ Also, it has been proposed that smaller branches are less likely to occlude compared to larger branches; however, there is no current literature that supports this. The ASA and LSA have a relatively rich collateral supply from cervical radiculopial or radiculomedullary branches. ${ }^{24-28}$ The ASA is comparatively well recognized and traverses the ventral aspect of the cord. The presence of up to two PSAs may or may not be found. Branches from the ASA and PSA/ LSA ramify on the surface and also within the substance of the spinal cord and medulla. Less well recognized is that the PSAs/LSAs may also anastomose rostrally with PICA branches at the restiform body and laterally at the emergence of the $\mathrm{C} 1-4$ nerve roots. ${ }^{29,30}$ In our study, the rates of vessel occlusion for the ASA and PSA/LSA were
$10.8 \%$ and $0 \%$, respectively. Even in the case of vessel occlusion, no clinically significant spinal cord infarct was identified in this cohort.

\section{Limitations of the Study}

One of the primary limitations of this study was the retrospective design; FD use was at the discretion of individual operators. Given the small diameter of the ASA and PSA/LSA, assessing vessel patency was at times difficult and dependent on the quality of imaging in the study. Although no screening for spinal cord infarction was performed, even minor ischemic insults would be expected to cause significant clinical deficits in this anatomical area; hence appropriate clinical follow-up was thought to be an adequate indicator of clinically relevant ischemic spinal cord complication. We concede that the small number of cases, which is inevitable given that this procedure is often viewed as a last-resort option, does not allow in-depth analysis of risk factors. It required a collaboration of 7 centers to collect enough cases to draw any conclusions on flow diverter coverage of ASA and PSA/LSA. Last, flow diverter technology and technique, as well as understanding of antiplatelet medication responsiveness, have evolved significantly over the 8.5-year study period.

\section{Conclusions}

Flow diverter coverage of the ASA or PSA/LSA was not associated with occlusion of these branches. In addition, there was no evidence of cervical spinal cord infarctions arising from FD treatment.

\section{References}

1. Brouillard AM, Sun X, Siddiqui AH, Lin N. The use of flow diversion for the treatment of intracranial aneurysms: expansion of indications. Cureus. 2016;8(1):e472.

2. Chua MMJ, Silveira L, Moore J, et al. Flow diversion for treatment of intracranial aneurysms: mechanism and implications. Ann Neurol. 2019;85(6):793-800.

3. Dmytriw AA, Phan K, Moore JM, et al. On flow diversion: the changing landscape of intracerebral aneurysm management. AJNR Am J Neuroradiol. 2019;40(4):591-600.

4. Walcott BP, Stapleton CJ, Choudhri O, Patel AB. Flow diversion for the treatment of intracranial aneurysms. JAMA Neurol. 2016;73(8):1002-1008.

5. Patel PD, Chalouhi N, Atallah E, et al. Off-label uses of the Pipeline embolization device: a review of the literature. Neurosurg Focus. 2017;42(6):E4.

6. Adeeb N, Griessenauer CJ, Dmytriw AA, et al. Risk of branch occlusion and ischemic complications with the Pipeline Embolization Device in the treatment of posterior circulation aneurysms. AJNR Am J Neuroradiol. 2018;39(7):13031309.

7. Awad AJ, Mascitelli JR, Haroun RR, et al. Endovascular management of fusiform aneurysms in the posterior circulation: the era of flow diversion. Neurosurg Focus. 2017;42(6):E14.

8. Dmytriw AA, Adeeb N, Kumar A, et al. Flow diversion for the treatment of basilar apex aneurysms. Neurosurgery. 2018;83(6):1298-1305.

9. Eller JL, Dumont TM, Mokin M, et al. Endovascular treatment of posterior circulation aneurysms. Neurol Res. 2014;36(4):339-343.

10. Toth G, Bain M, Hussain MS, et al. Posterior circulation flow 
diversion: a single-center experience and literature review. $J$ Neurointerv Surg. 2015;7(8):574-583.

11. Wang C-B, Shi W-W, Zhang G-X, et al. Flow diverter treatment of posterior circulation aneurysms. A meta-analysis. Neuroradiology. 2016;58(4):391-400.

12. Guerrero WR, Ortega-Gutierrez S, Hayakawa M, et al. Endovascular treatment of ruptured vertebrobasilar dissecting aneurysms using flow diversion embolization devices: singleinstitution experience. World Neurosurg. 2018;109:e164-e169.

13. Kiyofuji S, Graffeo CS, Perry A, et al. Meta-analysis of treatment outcomes of posterior circulation non-saccular aneurysms by flow diverters. J Neurointerv Surg. 2018;10(5):493-499.

14. Natarajan SK, Lin N, Sonig A, et al. The safety of Pipeline flow diversion in fusiform vertebrobasilar aneurysms: a consecutive case series with longer-term follow-up from a single US center. J Neurosurg. 2016;125(1):111-119.

15. Brinjikji W, Murad MH, Lanzino G, et al. Endovascular treatment of intracranial aneurysms with flow diverters: a meta-analysis. Stroke. 2013;44(2):442-447.

16. Siddiqui AH, Abla AA, Kan P, et al. Panacea or problem: flow diverters in the treatment of symptomatic large or giant fusiform vertebrobasilar aneurysms. J Neurosurg. 2012;116(6):1258-1266.

17. Griessenauer CJ, Ogilvy CS, Adeeb N, et al. Pipeline embolization of posterior circulation aneurysms: a multicenter study of 131 aneurysms. J Neurosurg. 2018;130(3):923-935.

18. Adix ML, Kaminsky IA, Choi IS. Ophthalmic artery occlusion after Pipeline Embolization Device placement with reconstitution of flow via an endoleak: a report of two cases. J Neurointerv Surg. 2017;9(7):686-688.

19. Brinjikji W, Lanzino G, Cloft HJ, Kallmes DF. Patency of the posterior communicating artery after flow diversion treatment of internal carotid artery aneurysms. Clin Neurol Neurosurg. 2014;120:84-88.

20. Dmytriw AA, Phan K, Salem MM, et al. The Pipeline Embolization Device: changes in practice and reduction of complications in the treatment of anterior circulation aneurysms in a multicenter cohort. Neurosurgery. 2020;86(2):266-271.

21. Rangel-Castilla L, Munich SA, Jaleel N, et al. Patency of anterior circulation branch vessels after Pipeline embolization: longer-term results from 82 aneurysm cases. J Neurosurg. 2017;126(4):1064-1069.

22. Raz E, Shapiro M, Becske T, et al. Anterior choroidal artery patency and clinical follow-up after coverage with the Pipeline Embolization Device. AJNR Am J Neuroradiol. 2015;36(5):937-942.

23. Wagner KM, Srinivasan VM, Srivatsan A, et al. Outcomes after coverage of lenticulostriate vessels by flow diverters: a multicenter experience. J Neurosurg. 2019;132(2):473-480.

24. Arslan M, Acar HI, Comert A, Tubbs RS. The cervical arteries: an anatomical study with application to avoid the nerve root and spinal cord blood supply. Turk Neurosurg. 2018;28(2):234-240.

25. Biglioli P, Spirito R, Roberto M, et al. The anterior spinal artery: the main arterial supply of the human spinal corda preliminary anatomic study. J Thorac Cardiovasc Surg. 2000;119(2):376-379.

26. Er U, Fraser K, Lanzino G. The anterior spinal artery origin: a microanatomical study. Spinal Cord. 2008;46(1):45-49.

27. Gailloud P. The artery of von Haller: a constant anterior radiculomedullary artery at the upper thoracic level. Neurosurgery. 2013;73(6):1034-1043.

28. Mercier P, Brassier G. Posterior spinal artery [letter]. J Neurosurg Spine. 2010;13(1):140.

29. Lasjaunias $P$, Vallee $B$, Person $H$, et al. The lateral spinal artery of the upper cervical spinal cord. Anatomy, normal variations, and angiographic aspects. J Neurosurg. 1985;63(2):235-241.

30. Tveten L. Spinal cord vascularity. I. Extraspinal sources of spinal cord arteries in man. Acta Radiol Diagn (Stockh). 1976;17(1):1-16.

\section{Disclosures}

Dr. Siddiqui has ownership interest in Amnis Therapeutics; BlinkTBI, Inc.; Buffalo Technology Partners, Inc.; Cardinal Consultants, LLC; Cerebrotech Medical Systems, Inc.; Cognition Medical; Endostream Medical, Ltd.; Imperative Care, Inc.; International Medical Distribution Partners; Neurovascular Diagnostics, Inc.; Apel Medical, Inc.; Rebound Therapeutics Corp. (purchased in 2019 by Integra LifeSciences Corp.); Rist Neurovascular, Inc.; Serenity Medical, Inc.; Silk Road Medical; Spinnaker Medical, Inc.; StimMed; Synchron; Three Rivers Medical, Inc.; and Viseon Spine, Inc. He is a consultant for Amnis Therapeutics; Boston Scientific; Canon Medical Systems USA, Inc.; Cerebrotech Medical Systems, Inc.; Cerenovus; Corindus, Inc.; Endostream Medical, Ltd.; Guidepoint Global Consulting; Imperative Care; Integra; Medtronic; MicroVention; Minnetronix Neuro, Inc.; Northwest University DSMB Chair for HEAT Trial; Penumbra; Apel Medical, Inc.; Rapid Medical; Rebound Therapeutics Corp.; Serenity Medical, Inc.; Silk Road Medical; StimMed; Stryker; Three Rivers Medical, Inc.; VasSol; and W.L. Gore \& Associates. He is National Principal Investigator or on steering committees for the following: Cerenovus NAPA Trial and ARISE II Trial; Medtronic SWIFT PRIME and SWIFT DIRECT Trials; MicroVention FRED Trial \& CONFIDENCE Study; MUSC POSITIVE Trial; Penumbra 3D Separator Trial; COMPASS Trial; and INVEST Trial. Dr. Levy has ownership interest in NeXtGen Biologics, RAPID Medical, Claret Medical, Cognition Medical, Imperative Care, Rebound Therapeutics, StimMed, and Three Rivers Medical. He receives honoraria from Medtronic, and he is a consultant for GLG Consulting, Guidepoint Global, Imperative Care, Claret Medical, Medtronic, Rebound, and StimMed. He is on the advisory board for NeXtGen Biologics. He renders medical/legal opinions as an expert witness. Dr. Cognard is a consultant for Stryker, Medtronic, Cerenovus, and MicroVention. Dr. Krings is a consultant for Medtronic, Penumbra, and Stryker. He has direct stock ownership in Marblehead, Inc., and receives royalties from Thieme. Dr. Thomas is on the Stryker Data Safety Monitoring Board for the SCENT Trial.

\section{Author Contributions}

Conception and design: Dmytriw, Kapadia, Enriquez-Marulanda, Parra-Fariñas, Kühn, Nicholson, Waqas, Marotta, Griessenauer. Acquisition of data: Dmytriw, Kapadia, Enriquez-Marulanda, Parra-Fariñas, Kühn, Nicholson, Waqas, Renieri, Foreman, Phan, Tutino, Marotta, Griessenauer. Analysis and interpretation of data: Dmytriw, Kapadia, Enriquez-Marulanda, Parra-Fariñas, Kühn, Nicholson, Waqas, Renieri, Michelozzi, Foreman, Phan, Tutino, Ogilvy, Radovanovic, Harrigan, Siddiqui, Levy, Limbucci, Cognard, Krings, Pereira, Thomas, Marotta, Griessenauer. Drafting the article: all authors. Critically revising the article: all authors. Reviewed submitted version of manuscript:

Dmytriw, Kapadia, Enriquez-Marulanda, Parra-Fariñas, Kühn, Nicholson, Waqas, Renieri, Foreman, Phan, Yang, Tutino, Ogilvy, Radovanovic, Siddiqui, Levy, Limbucci, Cognard, Krings, Pereira, Thomas, Marotta, Griessenauer. Approved the final version of the manuscript on behalf of all authors: Dmytriw. Statistical analysis: Dmytriw, Kapadia, Enriquez-Marulanda, Parra-Fariñas, Kühn, Nicholson, Waqas, Michelozzi, Foreman, Phan, Yang, Tutino. Administrative/technical/material support: Dmytriw, EnriquezMarulanda, Parra-Fariñas, Kühn, Nicholson, Phan, Tutino, Marotta, Griessenauer. Study supervision: Dmytriw, Marotta, Griessenauer.

\section{Correspondence}

Adam A. Dmytriw: St. Michael's Hospital, University of Toronto, Ontario, Canada.dmytriwa@smh.ca. 